the set of definitions is intended. The dust-cover declares that the "range", "scope" and "number" of "the more than 8,000 entries in this volume bring to those of many disciplines-from physicist to chemist, from aeronautical engineer to metallurgist-an invaluable aid for ready use in the laboratory, plant or office wherever mathematical applications are needed to-day".

To this end, the editors have obtained, from some forty distinguished authors and translators, contributions which are models of succinetness and these have been disposed in alphabetical order and cross-referenced. The terms defined range from "BetheSalpeter Equation" and "Blunder" to "Yang-Feldman Formalism and the S-Matrix" and "Year". This bespeaks comprehensiveness perhaps, but alas, too often it happens, in face of the requirement for accurate and concise definition, comprehensibility flies out of the window. Moreover, we may not follow her flight since, in general, we have not the radar of references. Nor do the essential multilingual indexes in German, Russian, French and Spanish help us in our difficulty.

Is this dictionary then a dead loss? (A term, by the way, it has not chosen to define.) Not entirely. But by its present standard of production it must count as a curate's ostrich egg; for besides the disparity of content, the typography shows many signs of inadequate proof correction (for example, SCARE, PYTHAGOREAN. What a title for schoolboys' science fiction !)

In according such a qualified reception to a work which must have taken a large number of man-hours, it remains to offer an opinion about the reasons for disappointment. Principally, it would appear that the contributors did not have a common audience or readership in their several minds. This is an editorial shortcoming basically, as to a large extent are the other faults mentioned above.

To obtain the standard expected of a good work of reference, a clearer vision of the likely consultant and his requirements, a considered policy for references and bibliography and greater care in proof correction seem essential.

The present edition may serve a limited purpose in libraries.

M. J. P. Musgrave

\section{A LEXICON FOR THE SCIENTIFIC ERA}

Webster's Third New International Dictionary of the English Language

Editor in Chief: Dr. Philip Babcock Gove. Unabridged. Pp. 56+2662. (London: G. Bell and Sons, Ltd.; Springfield, Mass.: G. and C. Merriam Co., 1961.) $420 s$.

ro quote the statement inside the jacket of this monumental work: "A new full-seale 'MerriamWebster' dictionary comes but once in a generation". It is now twenty-eight years since the last edition of this dictionary, or a dictionary planned on the 'International Webster', lines appeared. The present dictionary is, in fact, an entirely new one, being called Webster's Third New International Dictionary rather than the third edition of Webster's New International Dictionary.

While there has been a large number of additions and retractions from the 1934 edition, Webster's
Third New International Dictionary maintains the traditional Webster style, and, with more than 450,000 entries, many of which are illustrated, can be considered as almost an encyclopædia in miniature. It represents a great development on the second edition and to some extent as a reduction $(3,210 \mathrm{pp}$. to $2,662 \mathrm{pp}$.). This can be accounted for by the fact that not only has the Bibliographical Section been removed, but also the Gazetteer Section. The main developments and extensions lie in the way in which the editors have capably handled the flood of scientific, engineering and medical terms which have evolved during the past twenty-eight years. This has been admirably done by the permanent scientific editorial staff, supplemented by some eighty outside scientifie consultants.

Biologists are well served in that, besides explanations of general terminologies, family, specific and common names of animals and plants are listed and cross-referenced. For example, the description under the entry "Twayblade" is supplemented by referenco to "Listera" and "Liparis" and vice versa: "Beaver" gives reference to "Castor fiber" and vice versa, etc. For the chemist, elements and compounds are treated individually, and information is supplied concerning their properties, occurrence and uses, and in the case of elemonts this is followed by a detailed list of their more general compounds. The compounds ontered under "Nitrogen" extend to some two and a half columns of text. Named effects and laws in chemistry, physics and mathematics, including such entries as Bohr's theory, Krebs' cycle, Euler's formula, Stoke's law, etc,, are defined and explained. It is pleasing to see such terms as "Maser" defined, not only technically, but also from the etymological point of view, for it would be a great pity to lose track of the fact that such words are really only abbreviations - in this case, "microwave amplification by stimulated emission of radiation".

Mineralogical terms are defined and formulæ given to minerals with brief outlines of their properties; crystallographic forms are defined and usually illustrated. A full-page illustration is presented of man dealing with the muscular system and skeleton, and in general anatomical and physiological terms are well explained, and also pathological terms with an outline of their æetiology.

The edition which appeared in 1934 was priced at $85 s$. and could be considered to stand in good stead even against such works as the great Oxford English Dictionary. First, this was due to the disparity of prices, secondly, a utilitarian difference lay in the disparity of sizes. In a review of the second edition (Nature, 134,$603 ; 1934$ ) it was claimed that "Even the smallest study or office could accommodate "Webster" (which might indeed stand permanently on the corner of a desk), the O.E.D. spreads itself luxuriantly over several feet of shelf-room". This is still the case even with Webster's Third New International Dictionary at 21 guineas-- the production of which necessitated an outlay of more than $3,500,000$ dollars ( 11.25 million)-however, it would be necessary to have rather a large desk if one wanted to work and maintain Webster (approximately 10 in. $\times 13$ in. $\times$ 4 in.) on it.

Webster's International Dictionary was originally designed for the educated practical citizen of the world. It has now gone much further and is indeed a scholarly and technical reference work, a beneficial acquisition to any office or library.

R. J. Fifietin 